\title{
Formability of aluminum 1050A at high temperatures: Numerical modeling and experimental validation
}

\author{
Nejib Ghazouani ${ }^{\mathrm{a}, *}$ (D), Boulbaba Eladeb ${ }^{\mathrm{a}}$ (D), Mohammed A. Tashkandia ${ }^{\mathrm{D}}$, Mohamed Toumi Nasri ${ }^{\mathrm{b}}$ \\ a College of Engineering, Northern Border University, PO Box 1321 Arar, Northern Borders 73222, Saudi Arabia. \\ E-mail: nejib.ghazouani@nbu.edu.sa, eladebboulbaba@gmail.com,mohammd.tashkandi@nbu.edu.sa \\ b LMPE (LR18ES01), Ecole Nationale Supérieure d'Ingénieurs de Tunis (ENSIT), Université de Tunis, 5 Av. Taha Hussein, Montfleury 1008 \\ Tunis, Tunisia. E-mail: nasri.medtoumi@gmail.com
}

* Corresponding author

https://doi.org/10.1590/1679-78256523

\begin{abstract}
The sheet metals are prone to large plastic deformation during forming processes. The study purpose is to investigate $1050 \mathrm{~A}$ aluminum sheets thermomechanical behavior with ductile damage. A modified Swift model coupled to isotropic ductile damage and thermal effects was used. The forming parameters are introduced using Swift model coefficients and Erichsen index. An inverse identification procedure is applied to nonhomogeneous Erichsen test results. Bulge test is then used to validate the identified parameters. Erichsen test (Punch force vs displacement) results were obtained by experimental testing and simulation to build the objective function. Aluminum 1050A plasticity flow parameters and ductile damage variables were identified using a part of Erichsen test results. The remaining part of Erichsen test and bulge test results were used for validation. The numerical approach allowed the detection of failure zones with respect to thermal gradient induced by heat exchange. Within the isothermal condition, equivalent stresses and strains for 1050A Aluminum were obtained by simulations and experimental data.
\end{abstract}

\section{Keywords}

Erichsen test, hardening, damage, inverse identification, temperature and thermal gradient, Swift model.

\section{Graphical Abstract}
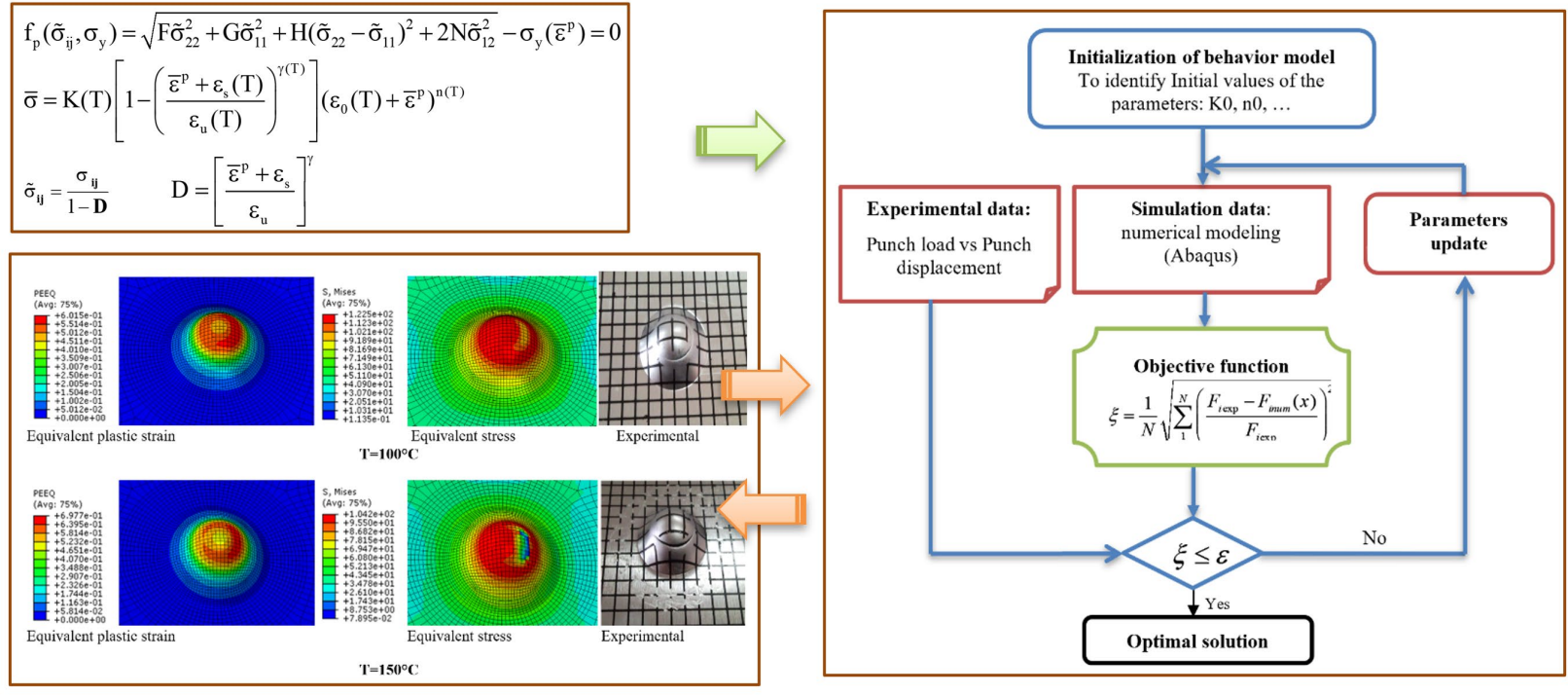


\section{INTRODUCTION}

The main concern of nowadays sheet metal industry is to keep readiness to always produce highly customizable (Lu, Liu, \& Wang, 2019) parts complying with increasing functional, competitional and quality requirements. Hence, workpieces should be lighter (Tisza \& Czinege, 2018; US EPA, 2016), cheaper, geometrically defects-free, eco-friendly (Cooper et al., 2017) and should no more require extra prototyping-induced costs and time. On the other hand, sheet metals are highly anisotropic (F. Barlat, 1987) due to their earlier processing (hot or cold rolling). Later, they will undergo large deformations during the forming processes (Banabic et al., 2000) (bulging, drawing, hydroforming...). Hence, adequate accounting for sheet metals intrinsic properties as well as of forming processes parameters (temperature, strain rate, lubrification...) allowed remarkable progress (Banabic, 2016; Banabic et al., 2010, 2020; Banabic et al., 2016; Nakagawa, 2000) in improving the modelling capabilities for such materials.

The numerical simulation with finite element analysis (Bong \& Lee, 2020; Keum \& Lee, 2000; Lee et al., 1997; Takuda et al., 2000; Yoon, 1999; Yoon et al., 1995; Yoon et al., 2002), the identification tests (Atkinson, 1997; Hussain \& Gao, 2007; Mahabunphachai \& Koç, 2008; Teaca et al., 2010; Xiao, 2019; Yoshida et al., 1998), and identification techniques (Abassi et al., 2013; Aguir et al., 2009; Aguir et al., 2011; Chakraborti, 2004; 2013) are the main pillars of this progress. World-class numerical predictions required for minimizing the time and cost due to manufacturing the prototypes are indeed related to the accuracy of the constitutive models used in the simulations. Identification models accounting for hardening, anisotropy, and ductile damage are still essential for the control design problems related particularly to spring back deformation, forming limits, dimensional tolerances, and cost of production (Achouri et al., 2014; Koç \& Altan, 2001; Naceur et al., 2006; Varma et al., 2007). Plastic forming of metal sheets with incremental strain rates and optimized load paths is the most used process. Definitely, a big deal of research work had been extensively published for hot forming processes characterization. For instance, material models that account for adverse effects during sheet metals forming processes (anisotropy, large plastic deformation, local stress concentrations, residual stresses...) have been developed. Recent reviews on advances made on sheet metals modelling (Ablat \& Qattawi, 2017; Banabic, 2016; Banabic et al., 2020; Zhang et al., 2018a) include detailed state-of-knowledge on physics-based approaches used which are variously based on bifurcation theory (Hill's and Swift models), geometrical imperfection theory (M-K models) and continuum damage mechanics CDM (GTN models, Lemaitre and Chaboche CDM coupled models). For a material model, the constitutive equations consist of a set of three types of functions: the yield criterion (Von Mises, Hill' 48 (Hill, 1948), Yld89, Yld91, Yld200-2d, Yld2004-18 (Barlat et al., 2003, 2005; Barlat \& Lian, 1989; Barlat et al., 1991), BBC, Etc....), the plastic potential and the hardening laws. Quadratic and non-quadratic yield criteria/functions were derived for above models with or without association with the plastic potential resulting in associated flow rule (AFR) models and non-associated flow rule models (NAFR), respectively. Among others, Stoughton developed a two-decade-long research work within the NAFR framework. In his work (Stoughton, 2002), the author questioned the validity and limitations of AFR-based models and introduced a NAFR model in which the plastic flow normality assumption (AFR) is relaxed. Since then, Stoughton et al (Lee et al., 2019; Lee et al., 2017; Lee et al., 2019; Stoughton, 2002; Stoughton \& Yoon, 2009, 2004) have carried out improvements and extended the initial NAFR-based model to a wider spectrum of applications to account for more complexities inherent to the sheet metals processing and/or forming processes. Another interesting physics-based approaches were developed within the thermodynamical framework and based on the pioneering works of LemaitreChaboche (Lemaitre, 1985; Chaboche, 1986, 1988; Lemaitre \& Chaboche, 1994) who provided sound scientific background for the continuum damage mechanics (CDM) . Later, Saanouni et co-workers used the CDM-approach and developed a thermodynamically-consistent model (TCM). Many applications of TCM where strong couplings (strong couplings (Badreddine et al., 2010; Lestriez et al., 2004; Msolli et al., 2015; Rajhi et al., 2014; Saanouni et al., 2010; Saanouni \& Hamed, 2013; Saanouni, 2012; Saanouni, Cherouat, \& Hammi, 2001; N'jock et al., 2020; Yue et al., 2019; Zhang et al., 2018b, 2019) were introduced based on the thermodynamics of irreversible processes (TIP) framework. Recently, other applications within the TIP framework were published. Gao et al. (Gao et al., 2020) characterized the behavior of AA7075 aluminum by thermal testing at a small punch. The GTN model is employed to characterize the damage of the sheet metal and applied to predict the formability and damage distribution of AA7075-T6 B-pillar part during the forming process. Ben Othmen et al. (Ben Othmen et al., 2020) predicted damage of stainless steel sheets by a ductile fracture model. They identified the model by simple tensile test. The results are used to study the behavior of the material during the Erichsen test. Ghorbel, et al. (Ghorbel et al., 2019) studied the behavior of the DD13 sheet metal by an anisotropic plasticity-damage model. The authors identified the model parameters by oriented tensile tests. For validation of this approach, they compared the numerical results to the results of the Erichsen cupping test.

For all above material models as well as theoretical developments, computational schemes (Ahmad et al., 2019; Cherouat et al., 2018; Gassara et al., 2009; Gatea et al., 2017; Hu et al., 2018; Robert et al., 2012; Zheng et al., 2017; Zhuang et al., 2016) were proposed including inverse identification methods, advanced Finite Element formulations, 
optimization schemes, implemented integration algorithms using various computing tools (Abaqus/Explicit@ finite element code/UMAT, VUMAT subroutines, combined programming language/numerical tools (Python, Fortran, Matlab,...). For the implementation cost, the schemes require computational time (algorithm development, CPU time) respective of the formulated approach's variables number. For instance, an approach using Barlat yield criteria (Yld89, Yld91, Yld200-2d, Yld2004-18) have to build computational integration procedure, for yield criterion solely, variables number ranging from to 4 to 16 (Pradeau, 2018).

To escape the material modelling approaches and their respective complicated computational procedures, approaches based on non-parametric data-driven (NP-DD) techniques (Abbassi et al., 2013; Hamdi Aguir et al., 2011; Chakraborti, 2004; Gorji, Mozaffar, Heidenreich, Cao, \& Mohr, 2020; Mohamed, Elatriby, Shi, \& Lin, 2016) were developed and included Artificial Neural Networks (ANNs), genetic algorithms (GA) and response surface methods (RSM). In (Mohamed et al., 2016), an ANN-based model is built using experimental data for predicting forming limit curves (FLCs) of AA5754 Aluminum Alloy sheets for temperatures within the range $\left(20-300^{\circ} \mathrm{C}\right)$ and forming rates within the range $(20-300 \mathrm{~mm} / \mathrm{s})$. More recently, a Fully-Connected Neural Networks (FCNNs) approach (Gorji et al., 2020) where Recurrent Neural Networks (RNNs) were used to model the anisotropic plane stress plasticity and reproduce the predictive results of the anisotropic plasticity models (Yld2000-2d) with homogeneous-yield-function-based anisotropic hardening (HAH).

A physics-based approach is developed within the present study. Unlike similar approaches, the objective is to reduce predictive model complexity (only 10 constitutive parameters are introduced). More advantage of the approach is conducting identification and validation using numerical simulation at reasonable computational cost and low-cost experimentation with no compromise to the predictive capacity and accuracy. To this end, a modified Swift model coupled with an isotropic ductile damage and thermal effects is built. The forming parameters are introduced via the modified Swift model coefficients and the Erichsen index. An inverse identification procedure using a complex algorithm in MATLAB (C) code is applied to the results of the modified non-homogeneous Erichsen test for 1050A aluminum sheets. Bulge test is then conducted to validate the thermomechanical constitutive model. Furthermore, numerical simulations by means of Abaqus/standard $(\subset$ allows the modeling of the Erichsen test whose results are utilized to correlate Erichsen index to the critical plastic strains.

\section{METHODS AND MATERIALS}

\subsection{Theoretical formulation}

An associated flow rule for which the yield surface is used for together modelling plasticity and isotropic damage. A previous work (Ayadi et al., 2009) includes full details on the coupled isothermal formulation.

Considering Hill ' 48 quadratic criterion coupled to isotropic ductile damage represented by the scalar $D$, we have established in the previous study (Ayadi et al., 2009) the plane stress relationship:

$$
\mathrm{f}_{\mathrm{p}}\left(\tilde{\sigma}_{\mathrm{ij}}, \sigma_{\mathrm{y}}\right)=\sqrt{\mathrm{F} \tilde{\sigma}_{22}^{2}+\mathrm{G} \tilde{\sigma}_{11}^{2}+\mathrm{H}\left(\tilde{\sigma}_{22}-\tilde{\sigma}_{11}\right)^{2}+2 \mathrm{~N} \tilde{\sigma}_{12}^{2}}-\sigma_{\mathrm{y}}\left(\bar{\varepsilon}^{\mathrm{p}}\right)=0
$$

Where $\sigma_{\mathrm{y}}$ is the material yield stress, $\left(\mathrm{F}, \mathrm{G}, \mathrm{H}\right.$ and $\mathrm{N}$ ) are the initial plastic anisotropy parameters and $\tilde{\sigma}_{\mathrm{ij}}$ are the Cauchy stress's components. The coupling of effective stress is given by:

$$
\tilde{\sigma}_{\mathrm{ij}}=\frac{\sigma_{\mathrm{ij}}}{1-\mathbf{D}}
$$

Where $D$ is a variable to account for the ductile damage in terms of the plastic strain (Abbassi et al., 2013) by:

$$
\mathrm{D}=\left[\frac{\bar{\varepsilon}^{\mathrm{p}}+\varepsilon_{\mathrm{s}}}{\varepsilon_{\mathrm{u}}}\right]^{\gamma}
$$

In reference to (Abbassi et al., 2013), the cumulative strains $\varepsilon_{\mathrm{s}}$ and $\varepsilon_{\mathrm{u}}$ are measures of the material ability to form, $(\gamma)$

is a measure of damage severity. To numerically identify $\varepsilon_{s}, \varepsilon_{u}$, and $(\gamma)$, the inverse identification method is applied to 
Erichsen test. The modified Swift model where the coupling of hardening plastic flow and ductile damage are included, is expressed in (Ayadi et al., 2009) by:

$\bar{\sigma}=K(T)\left[1-\left(\frac{\bar{\varepsilon}^{\mathrm{p}}+\varepsilon_{\mathrm{s}}(\mathrm{T})}{\varepsilon_{\mathrm{u}}(\mathrm{T})}\right)^{\gamma(\mathrm{T})}\right]\left(\varepsilon_{0}(\mathrm{~T})+\bar{\varepsilon}^{\mathrm{p}}\right)^{\mathrm{n}(\mathrm{T})}$

The Identification of the parameters $\mathrm{F}, \mathrm{G}, \mathrm{H}$ and $\mathrm{N}$ using $0^{\circ}, 45^{\circ}$ and $90^{\circ}$ oriented tensile tests as shown in Figures 1 and 2.

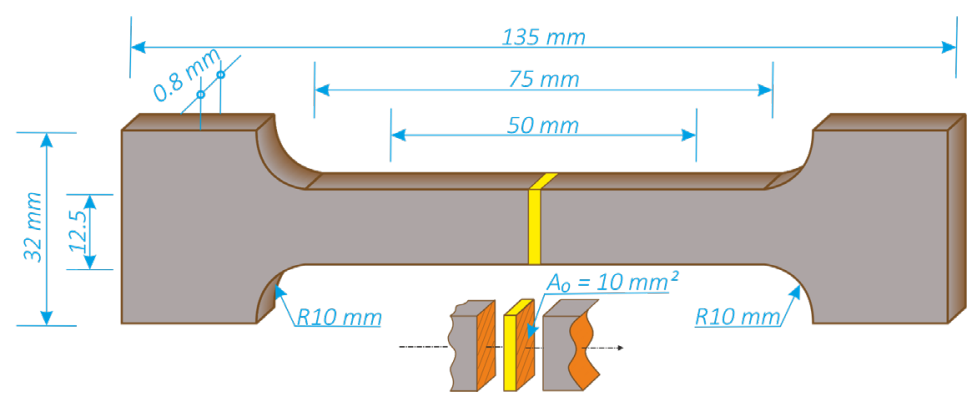

Figure 1: Standard dimensions of tensile specimens.

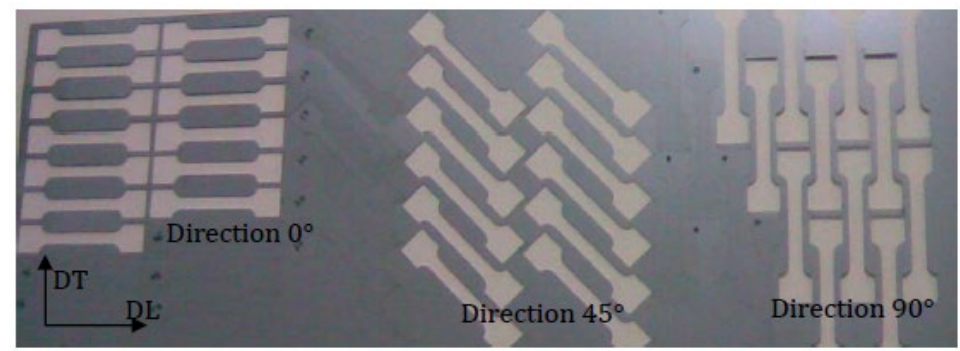

Figure 2: Orientations of the directions of tensile specimens

The components of the stress tensor resulting from the normal stress according to $\mathrm{x}$ are written in the form:

$\sigma_{11}=\sigma \cos ^{2} \theta, \sigma_{22}=\sigma \sin ^{2} \theta$ et $\sigma_{12}=\sigma \cos \theta \sin \theta$

the equivalent stress becomes:

$2 \sigma_{e q}^{2}=\left[F \sin ^{4} \theta+G \cos ^{4} \theta+H\left(\sin ^{2} \theta-\cos ^{2} \theta\right)^{2}+2 N \cos ^{2} \theta \sin ^{2} \theta\right] \sigma^{2}$

The law of normality, the relationships between stresses and strains are written:

$d \varepsilon_{11}=\left(G \sigma_{11}+H\left(\sigma_{11}-\sigma_{22}\right)\right) d \lambda$

$d \varepsilon_{22}=\left(F \sigma_{22}+H\left(\sigma_{22}-\sigma_{11}\right)\right) d \lambda$

$d \varepsilon_{33}=-\left(F \sigma_{22}+G \sigma_{11}\right) d \lambda$

$d \varepsilon_{12}=2 N \sigma_{12} d \lambda$

Where $d \lambda$ is the plastic multiplier.

For an oriented tensile test, the Lankford anisotropy coefficient is defined by the following equation: 
$r_{\theta}=\frac{d \varepsilon_{y y}}{d \varepsilon_{z z}}$

The angle of the oriented tensile test gives

$d \varepsilon_{33}=d \varepsilon_{z z}$ et $r_{\theta}=\frac{H+(2 N-G-F-4 H) \cos ^{2} \theta \sin ^{2} \theta}{F \sin ^{2} \theta+G \cos ^{2} \theta}$

The equivalence of plastic energy gives

$\sigma_{e q} d \varepsilon_{e q}=\sigma d \varepsilon$

The Hill48 parameters are determined as a function on the Lankford parameters $r_{0}, r_{45}$ and $r_{90}$ :

$$
\left\{\begin{array}{c}
F=\frac{r_{0}}{r_{90}\left(1+r_{0}\right)} \\
G=\frac{1}{1+r_{0}} \\
H=\frac{r_{0}}{1+r_{0}} \\
N=\frac{\left(r_{0}+r_{90}\right)\left(2 r_{45}+1\right)}{2 r_{90}\left(1+r_{0}\right)}
\end{array}\right.
$$

A characterization methodology of the above model's parameters is detailed in (Aguir et al., 2011; Li \& He, 2013). The elastoplastic behavior model coupled with ductile damage, is characterized by the following parameters:

- Three parameters to account for Swift's model hardening plastic flow: $K, \varepsilon_{0}$, and $n$;

- $\quad$ Four Parameters of Hill '48 quadratic criterion F, G, H and N;

- $\quad$ Three coefficients to account for the ductile damage: $\varepsilon_{u}, \varepsilon_{s}$, and $\gamma$;

The material model parameters obtained are chosen to faithfully account for the sheet metals behavior. Moreover, they allow improving the formability of Aluminum sheets, investigating the effect of thermal gradient on the formability of Aluminum sheets, predicting the failure zones by establishing adequate mathematical correlations. During forming operations, their use is crucial to predict the sheet metals behavior for both lab and industrial scales. To this purpose, they need to be identified numerically using the inverse method (Nelder-Mead simplex optimization technique developed in MATLAB (C) and then validated using experimental data.

\subsection{Experimental set-up of the Erichsen test}

The test protocol was invented by engineer A.M Erichsen in 1910, and it was the first test method for determining the quality class of sheet metals. Erichsen test was carried out by the depression of a hemispherical punch on a metal sheet stuck on a blank holder, to the failure of the sheet. The depths measured (in $\mathrm{mm}$ ) give the Erichsen Index (I.E.) and a measure of the ductility of the sheets in the working plane under the condition of plane stresses.

Annealed 1050A aluminum is known for its formability at room temperature or at elevated temperatures. It is preferred by forming industry because of its low density, which is roughly one-third of steel and copper. It is used in all sectors of industry, especially aerospace due to reduced weight and therefore energy savings. The chemical composition (in percent of weight) of this aluminum grade is reported in (Table 1)

Table 1 Chemical composition in \% of weight for annealed 1050A aluminum.

\begin{tabular}{cccccccccc}
\hline $\mathrm{Cu}$ & $\mathbf{M g}$ & $\mathbf{S i}$ & $\mathrm{Fe}$ & $\mathbf{M n}$ & $\mathrm{Zn}$ & $\mathrm{Ti}$ & $\mathbf{N}$ & Al \\
\hline 0.05 & 0.05 & 0.25 & 0.05 & 0.05 & 0.07 & 0.05 & 0.05 & $>99.5$ \\
\hline
\end{tabular}


During Erichsen test (Figure 3), a square shaped $(90 \times 90 \mathrm{~mm}$ ) and $0.8 \mathrm{~mm}$ thick $1050 \mathrm{~A}$ aluminum sheet specimen is cut by a laser machine. A $10 \mathrm{kN}$ force is used to tighten the sheet between the die and the blank-holder.

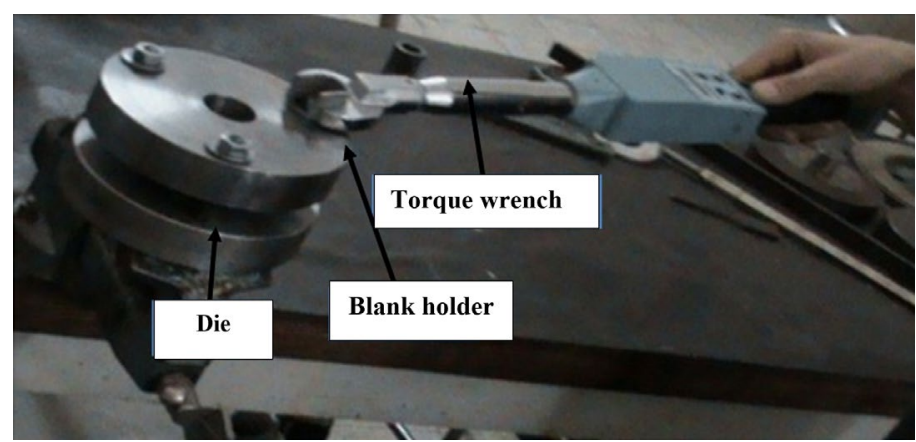

Figure 3: Tightening of the sheet with a torque wrench

The Erichsen device is mounted on an SKF tensile machine with $200 \mathrm{KN}$ maximum load capacity (Figure 2). The punch force, as well as its penetration depth, are measured by a multi-axial force sensor with model reference FN7325 (for which the maximum load is $7.5 \mathrm{KN}$ ). A data acquisition DAQ ensures measurement recording on a computer. Table 2 summarizes the temperatures of different parts during the test.

Table 2 Temperatures of different parts during the test.

\begin{tabular}{cccc}
\hline Test temperature $\left({ }^{\circ} \mathrm{C}\right)$ & Die temperature $\left({ }^{\circ} \mathrm{C}\right)$ & Punch Temperature $\left({ }^{\circ} \mathrm{C}\right)$ & Flan Temperature $\left({ }^{\circ} \mathrm{C}\right)$ \\
\hline 20 & 20 & 20 & 20 \\
100 & 100 & 38 & 100 \\
150 & 150 & 40 & 150 \\
200 & 200 & 52 & 200 \\
250 & 250 & 58 & 250 \\
300 & 300 & 74 & 300 \\
\hline
\end{tabular}

Erichsen test (Figure 4) was conducted for different temperatures applied to the sheet in the due experimental protocol described in (Zribi et al., 2013):

- $\quad$ The sheet is tightly inserted between the die and blank-holder. A heater is placed around the die perimeter.

- A thermal insulator attached to a temperature control and servo unit (Zribi et al., 2013) was introduced to reduce the heat loss outside the experiment device.

- The control system is used to ensure the target temperature is attainted and remains unchanged for almost 15 min till the isothermal condition is established.

- As there is no independent control of the punch temperature in the original test configuration, a temperature control and servo unit are designed, made and connected to the die. When the isothermal condition is established, the punch starts by stretching the test specimen. Simultaneously, response force and punch displacements are recorded. The procedure is identically reiterated for every temperature level. 


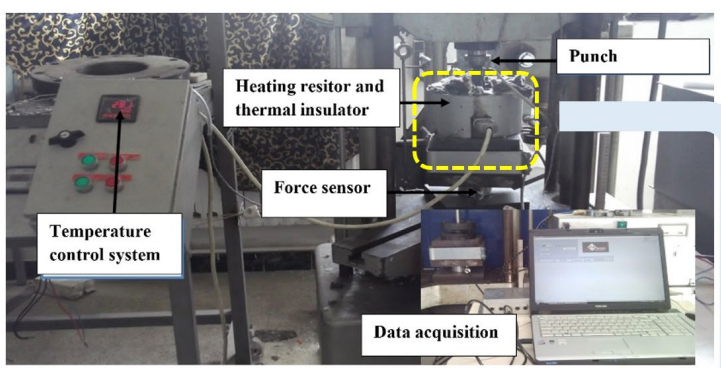

(a)

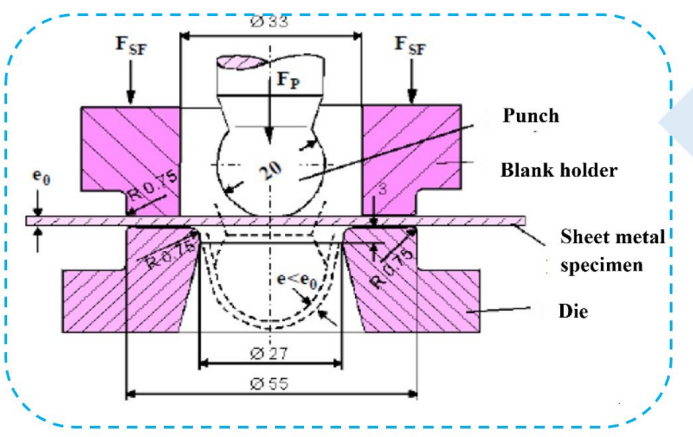

(d)

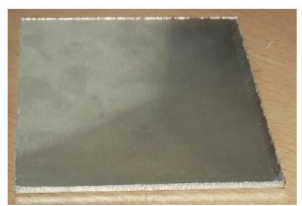

(b)

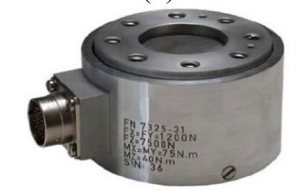

(c)

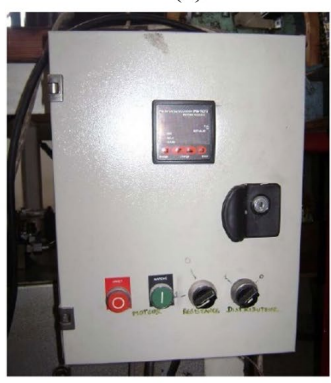

(e)

Figure 4: Modified Erichsen test - (a): experimental set-up, (b): 1050 A square 1050A aluminum specimen, (c): Force Sensor FN7325, (d): working principle and dimension (Manesh \& Taheri, 2003), (e): Temperature control and servo unit

\subsection{Experimental set-up of the bulge test}

The experimental device of the hydraulic bulge test consists of four sub-systems:

- $\quad$ System for clamping the test specimen (Figure 5. a).

- Hydraulic Sub-system whose the role consists in supplying the necessary power for sheet forming.

- Heating and temperature regulation unit used for converting electrical energy into heat energy and controlling the heating temperature of the specimen (Figure 5. d).

- Electric control circuit to supply electrical energy to the heating system and hydraulic installation (Figure 5. d).

A protective cover has been designed using tempered glass to protect the experimenter against jets of hot pressurized liquid which may occur during a sudden burst of the sheet (Figure 5. e)
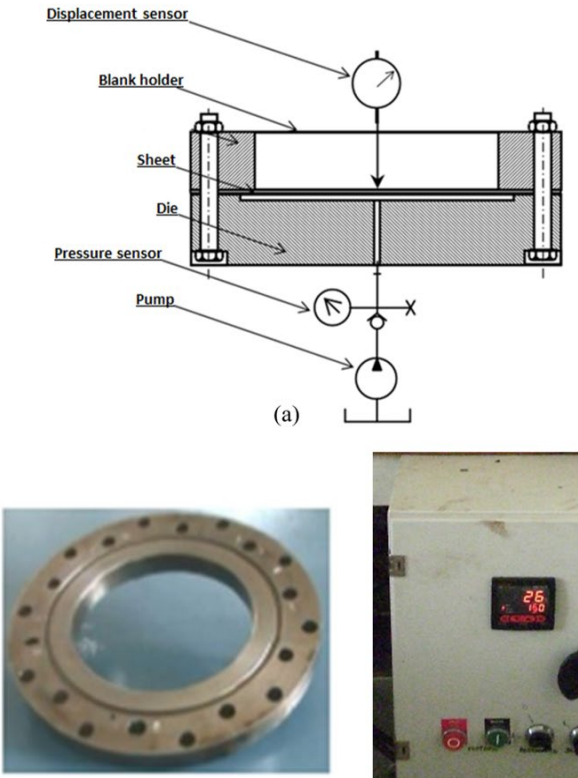

(c)

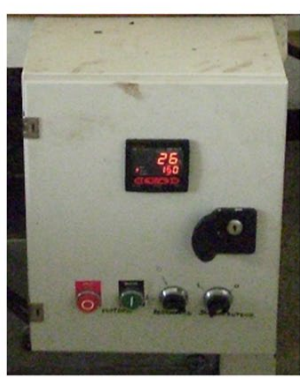

(d)

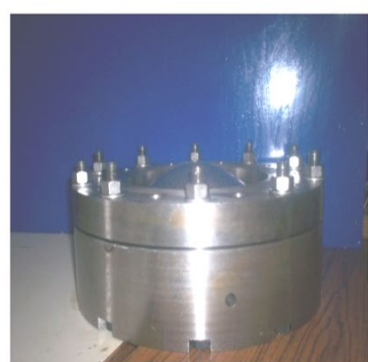

(b)

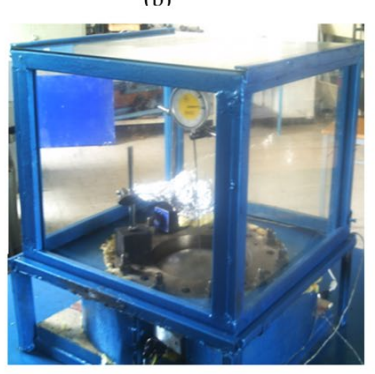

(e)

Figure 5: The testing apparatus used for the hydraulic bulge test- (a): working principle, (b): specimen clamping unit, (c): circular blank-holder, (d): thermal control system, (e): thermal insulation system 
The sheets are cut into circular specimen (330 mm diameter and $0.8 \mathrm{~mm}$ thickness). The active part of the circular blank-holder is $200 \mathrm{~mm}$ diameter. The bulge test was conducted for three temperatures $15^{\circ} \mathrm{C}, 50^{\circ} \mathrm{C}$ and $100^{\circ} \mathrm{C}$. The sheet is clamped between the die and the blank-holder, the thermal resistor is installed at the die perimeter. The temperature of the test is maintained for 15 min to reach the isothermal condition.

\subsection{Material model characterization method}

The model characterization method used is thoroughly detailed in (Aguir et al., 2011; Li \& He, 2013). A full depiction of the method is given in (Figure 6).

The method can be summerized as follows:

- $\quad$ Step 1: Identification of the hardening model's $\left(K, \varepsilon_{0}\right.$, and $\left.n\right)$ without damage coupling ( $D$ is set equal to zero),

- Step 2: Identification of the Hill '48 quadratic criterion F, G, H and N and hardening parameters are fixed.

- $\quad$ Step 3: Identification of the coupled Swift model $\left(\gamma, \varepsilon_{\mathrm{s}}\right.$, and $\left.\varepsilon_{\mathrm{u}}\right)$, with Lankford coefficients fixed, and the hardening parameters identified in step 1.

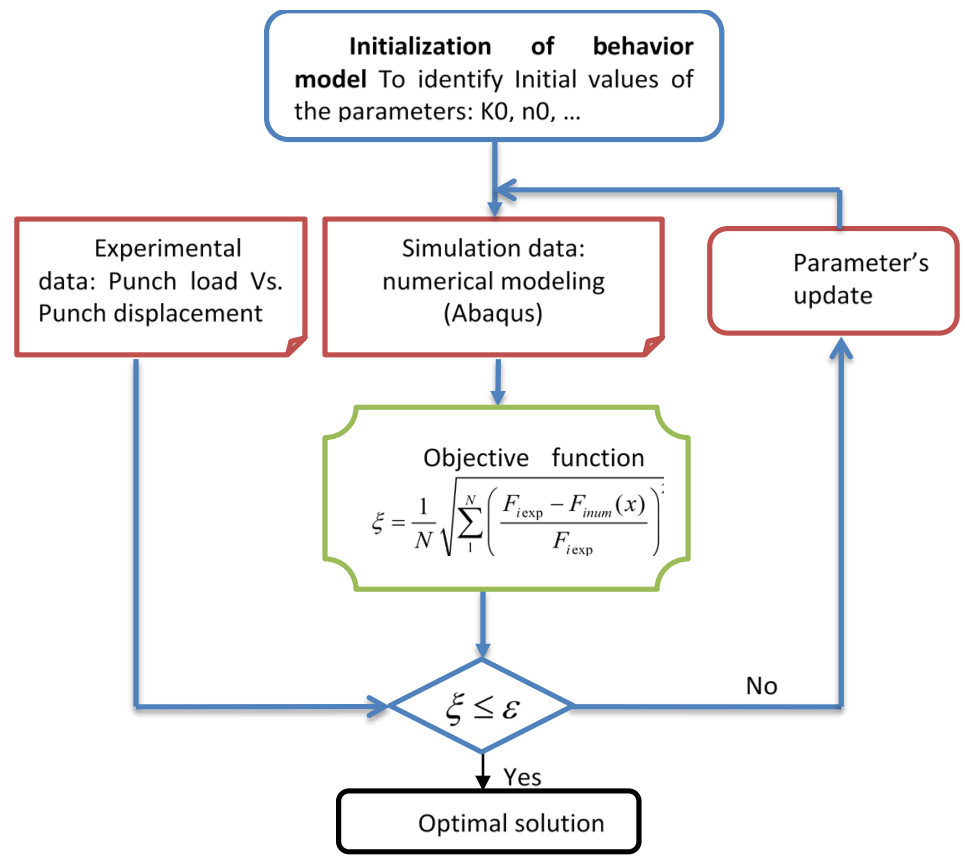

Figure 6: Identification procedure by the inverse method (Hamdi Aguir et al., 2011; Li \& He, 2013).

The modified Erichsen test results were obtained while temperatures are steadily varying and strain rate kept constant. The parameters of the modified Swift model coupled to damage $\left(K, n, \varepsilon_{0}, \varepsilon_{s}, \varepsilon_{u}\right.$ and $\gamma$ ) and Erichsen index (E.I.) are calculated as function of the temperature acting on the specimen. The strength-hardening coefficient average values $(K)$, strain-hardening exponent $(n)$, the damage $\left(\varepsilon_{s}, \varepsilon_{u}, \gamma\right)$ and the Erichsen Index (E.I.) were evaluated using inverse identification method. The parameters of Swift model coupled to damage (4) and Erichsen Index (E.I.) are expected to be dependent of the temperature's variation. Hence, the optimal solution for hardening and damage behavior parameters should minimize the numerical/experimental results error gap. The objective function (Figure 6) calculates the error gap between the $\mathrm{N}$ test data of the tensions from the Erichsen test and their numerical predictions (Figure 7 ) using the objective function below:

$\xi_{r_{0} ; r_{45} ; r_{90}}=\frac{1}{N} \sqrt{\sum_{1}^{N}\left(\frac{F_{i \exp }-F_{\text {inum }}}{F_{i \exp }}\right)^{2}}$

Where $F_{\text {iexp }}$ is the test punch force corresponding to $i^{\text {th }}$ punch displacement $\delta_{i}, F_{\text {inum }}$ is the numerically simulated punch force, and $N$ the number of test data. 


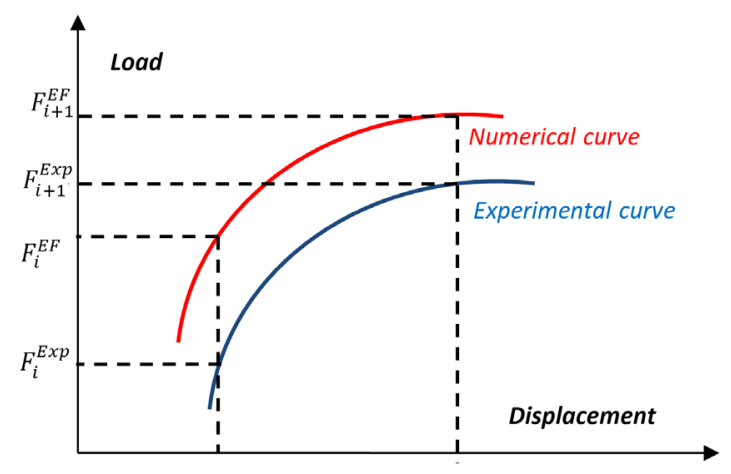

Figure 7: Relative error from simulation/test results

\section{RESULTS AND DISCUSSION}

\subsection{Modified Swift Model identification}

Table $3 a$ and $3 b$ show the values of $K, n, \varepsilon_{0}, \varepsilon_{s}, \varepsilon_{u}, \gamma, F, G, H, N$ and E.I. obtained using the inverse identification technique (simplex algorithm implemented in MATLAB @); fminsearch function (van den Boogaard, 2004)).

Table 3a Parameters of materials obtained by inverse identification technique at different temperatures.

\begin{tabular}{|c|c|c|c|c|c|c|c|}
\hline \multirow{2}{*}{ Temperature $\left({ }^{\circ} \mathrm{C}\right)$} & \multicolumn{3}{|c|}{ Hardening parameters } & \multicolumn{3}{|c|}{ Hardening parameters } & \multirow{2}{*}{ E.I. $(\mathrm{mm})$} \\
\hline & $\mathrm{K}(\mathrm{MPa})$ & $\varepsilon_{0}$ & $\mathbf{n}$ & $\varepsilon_{\mathrm{s}}$ & $\varepsilon_{\mathrm{u}}$ & $\gamma$ & \\
\hline 20 & 161.8 & 0.008 & 0.315 & 0.013 & 0.54 & 9.45 & 9.440261 \\
\hline 100 & 128.301 & 0.009 & 0.252 & 0.004 & 0.662 & 14.409 & 9.440577 \\
\hline 150 & 106.715 & 0.009 & 0.248 & 0.011 & 0.715 & 15.269 & 9.840418 \\
\hline 200 & 83 & 0.009 & 0.24 & 0.01 & 0.76 & 16.533 & 10.05061 \\
\hline
\end{tabular}

Table $\mathbf{3 b}$ Identification of the anisotropy parameters.

\begin{tabular}{|c|c|c|c|c|c|c|c|}
\hline \multirow{2}{*}{ Temperature $\left({ }^{\circ} \mathrm{C}\right)$} & \multicolumn{3}{|c|}{ Lankford coefficients } & \multicolumn{4}{|c|}{ Hill'48 parameters } \\
\hline & $r_{0}$ & $r_{45}$ & $r_{90}$ & $\mathbf{F}$ & G & $\mathrm{H}$ & $\mathbf{N}$ \\
\hline 20 & 1.02 & 0.927 & 0.397 & 0.52 & 0.49 & 0.50 & 1.44 \\
\hline 100 & 0.98 & 1.63 & 0.505 & 0.98 & 0.50 & 0.49 & 3.16 \\
\hline 150 & 1 & 1.209 & 0.38 & 1.31 & 0.5 & 0.5 & 3.10 \\
\hline 200 & 1.12 & 1.034 & 1.02 & 0.51 & 0.47 & 0.52 & 1.51 \\
\hline
\end{tabular}

Figure 8 illustrates, for different thermal loadings, the experimental/numerical results as shown by the curve of the punching force vs. punch depth in good agreement.

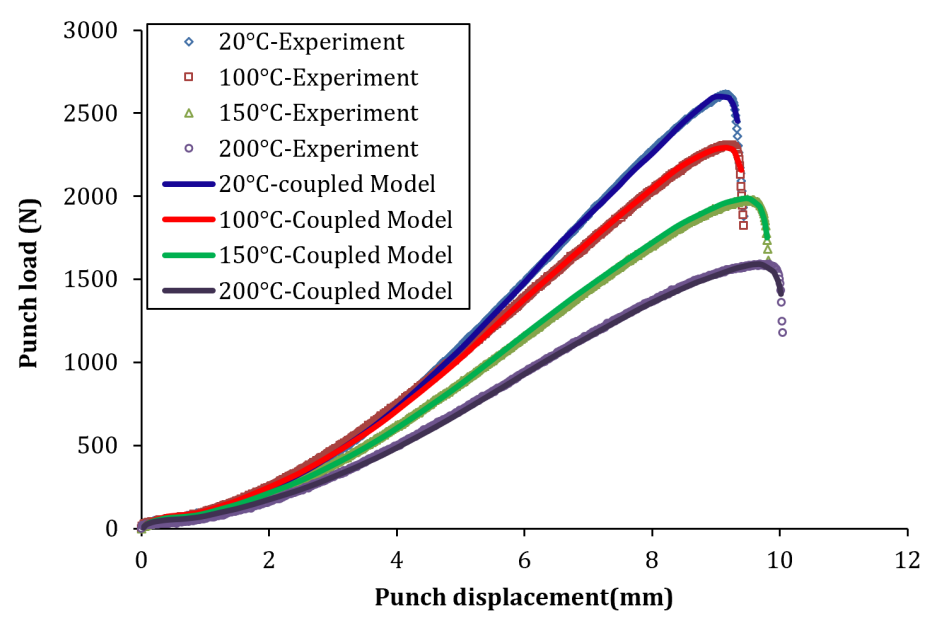

Figure 8: Material model identification using modified Erichsen test results: numerical/experimental curves fitting for punch force vs. displacement for temperatures in the range $\left[20^{\circ} \mathrm{C}-200^{\circ} \mathrm{C}\right]$ 
Figure 9 and Figure 10 show respectively the temperature-dependent variations of the plasticity flow parameters ( $n$ and $K$ ) and the ductile damage variables ( $\gamma$ and $\varepsilon_{u}$ ).
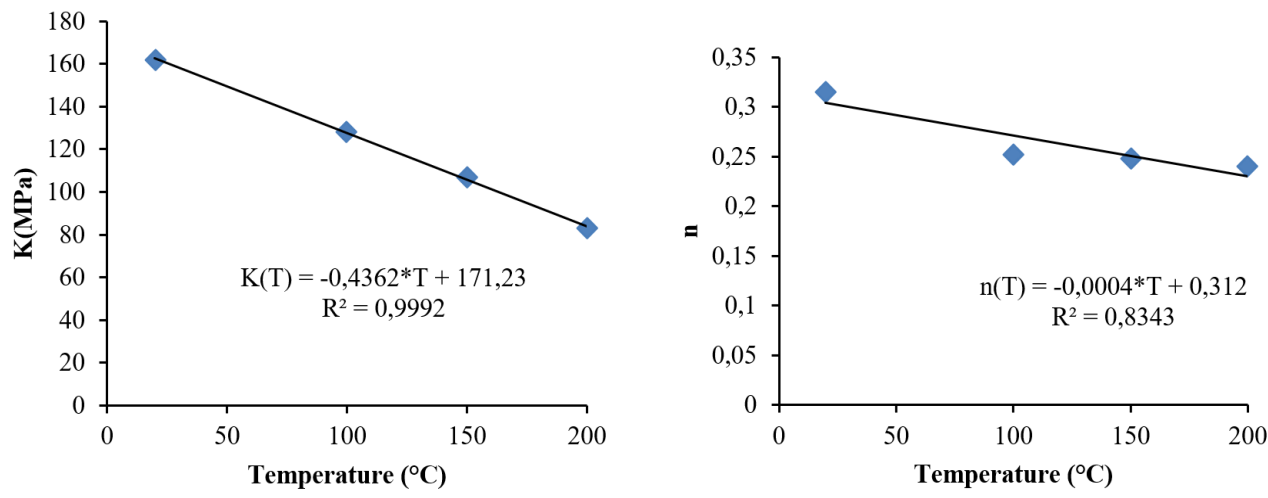

Figure 9: Temperature correlation for 1050A Aluminum with (a): work hardening coefficient (K), (b): strain hardening exponent ( $\mathrm{n}$ )
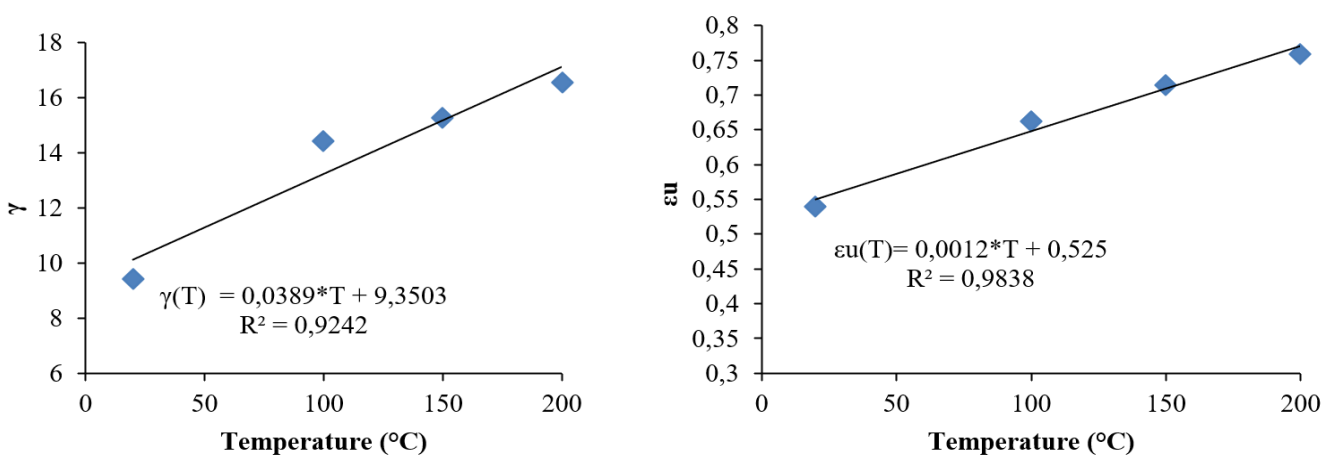

Figure 10: Temperature correlation for 1050A Aluminum with ductile damage coefficients (a) exponent $(\nu)$, (b) strain $(\varepsilon u)$

To assess the quality of the identified model, a calculation of relative errors between numerical predictions is compared to the experimental results. Table 4 summarizes the relative errors in the estimated parameters of the temperature-dependent Swift model coupled to isotropic damage.

Table 4 Relative error between experimental and numerical results.

\begin{tabular}{cccc}
\hline Temperature $\left({ }^{\circ} \mathrm{C}\right)$ & $\begin{array}{c}\text { Percent error of forces } \\
\text { (uncoupled model) (\%) }\end{array}$ & $\begin{array}{c}\text { Percent error of forces } \\
\text { (coupled model) (\%) }\end{array}$ & $\begin{array}{c}\text { Percent error of Erichsen index } \\
\text { (E.I.) (coupled model) (\%) }\end{array}$ \\
\hline 20 & 0.1 & 0.09 & 1.048 \\
100 & 0.1 & 0.1 & 0.413 \\
150 & 0.1 & 0.1 & 0.396 \\
200 & 0.2 & 0.2 & 0.298 \\
\hline
\end{tabular}

\subsection{Validation of the identification method/results}

\subsubsection{Erichsen test}

To validate the identification method, we used the above obtained equations of the parameters $K(T), n(T), \varepsilon u(T)$ and $\gamma(T)$ to predict the same parameters for the two temperatures $250^{\circ} \mathrm{C}$ and $300^{\circ} \mathrm{C}$ for which we already have the Erichsen test results. Table 5 summarizes the values of the hardening and damage parameters calculated using linear regression method.

Table 5 Parameters of materials at temperatures $250^{\circ} \mathrm{C}$ and $300^{\circ} \mathrm{C}$.

\begin{tabular}{|c|c|c|c|c|c|c|}
\hline \multirow{2}{*}{ Temperature $\left({ }^{\circ} \mathrm{C}\right)$} & \multicolumn{3}{|c|}{ Hardening parameters } & \multicolumn{3}{|c|}{ Damage parameters } \\
\hline & $\mathrm{K}(\mathrm{MPa})$ & $\varepsilon_{0}$ & $\mathrm{n}$ & $\varepsilon_{\mathrm{s}}$ & $\varepsilon_{\mathrm{u}}$ & $\gamma$ \\
\hline 250 & 62.180 & 0.009 & 0.212 & 0.010 & 0.825 & 19.075 \\
\hline 300 & 40.370 & 0.009 & 0.192 & 0.001 & 0.885 & 21.020 \\
\hline
\end{tabular}


The Swift model prediction results are in close correlation with test data (Figure 11) for both temperatures selected for validation.

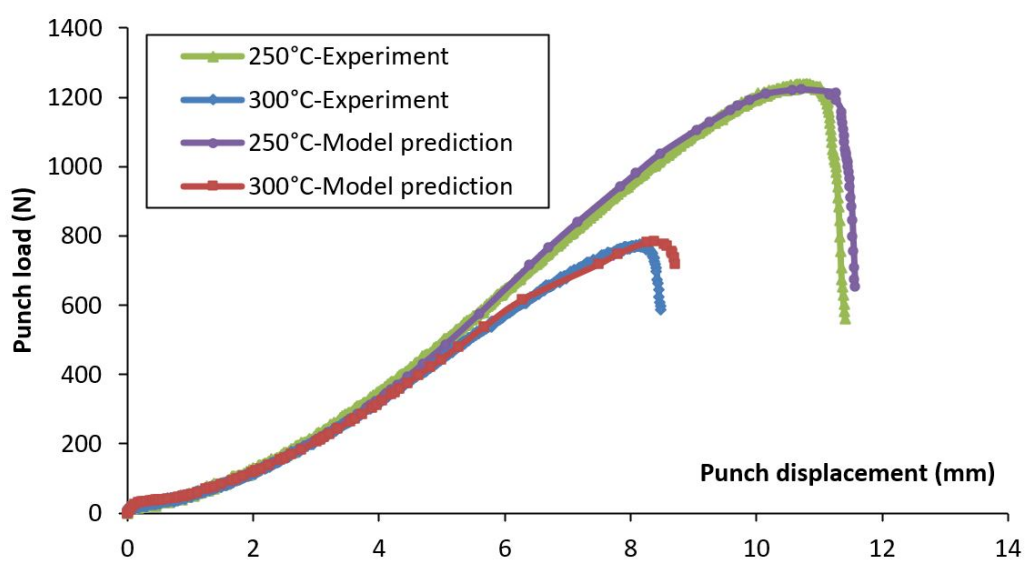

Figure 11: Validation of material behavior model using the Erichsen test results for the two temperatures $250^{\circ} \mathrm{C}$ and $300^{\circ} \mathrm{C}$

Table 6 illustrates the mechanical properties of 1050A aluminum sheets at different temperatures.

Figure 12 summarizes the distribution of the mechanical quantities (equivalent stress and plastic strain) at maximum displacement which corresponds to the sheet yield state.

Table 6 Mechanical characteristics of 1050A Aluminum.

\begin{tabular}{cccc}
\hline Temperature $\left({ }^{\circ} \mathrm{C}\right)$ & Maximum stress at failure $(\mathrm{MPa})$ & Yield strength $(\mathrm{MPa})$ & Strain at failure \\
\hline 20 & 114.565 & 35.367 & 0.526 \\
100 & 106.116 & 39.147 & 0.657 \\
150 & 90.265 & 33.180 & 0.703 \\
200 & 71.988 & 26.797 & 0.749 \\
250 & 52.720 & 17.889 & 0.871 \\
300 & 42.230 & 12.021 & 0.902 \\
\hline
\end{tabular}

Under isothermal condition, a concentration of the damage is observed at the edge of the punch-sheet contact zone for $9 \mathrm{~mm}$ displacement. The equivalent stress in these elements tends to be zero. We notice a rapid propagation of the damage for a displacement greater than $9 \mathrm{~mm}$. The location of the damage appears in the form of a circular area. For the temperatures below $150{ }^{\circ} \mathrm{C}$, the experimentally observed failure zones perfectly match the damage zones detected by numerical simulations. Hence, the used identification procedure accuracy and its capability to predict the damage areas for sheet metals undergoing isothermal forming process is proven.

Figure 13 depicts the variation of the damage in terms of the equivalent plastic strain for different temperatures. The identification results show that at the temperature $20{ }^{\circ} \mathrm{C}$ the damage exceeding $2.5 \%$ is observed for plastic strain greater than $35 \%$. For this same level of damage, the plastic strain reaches $70 \%$ and the specimen temperature reaches $250{ }^{\circ} \mathrm{C}$. This proves that the damage process can be significantly retarded by acting on the temperature of the blankholder when the forming process is running. Besides, the temperature-dependent increase of the critical plastic strain results in the following:

- $\quad$ the increase of the sheet surface

- $\quad$ large thinning of the sheet

- $\quad$ increase of the sheet metal forming limits 


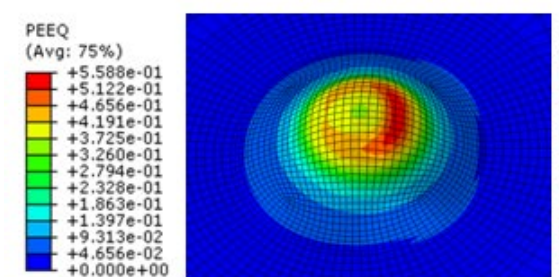

Equivalent plastic strain

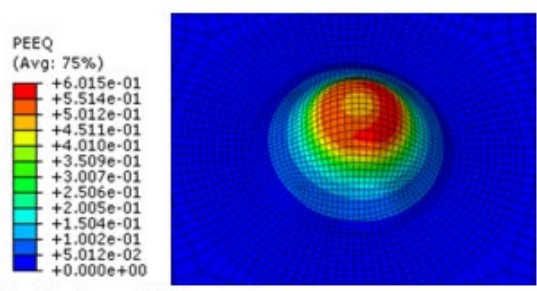

Equivalent plastic strain

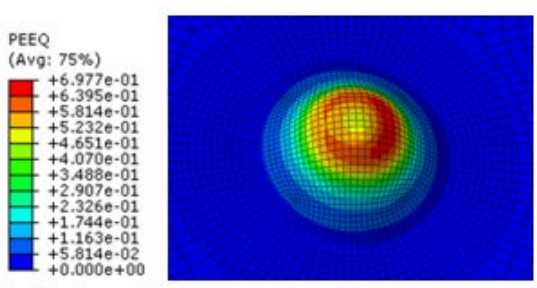

Equivalent plastic strain

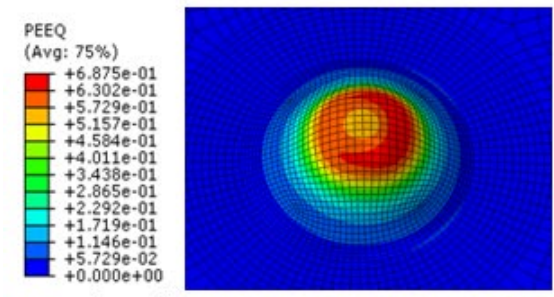

Equivalent plastic strain

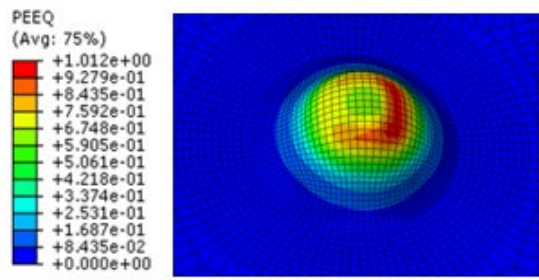

Equivalent plastic strain

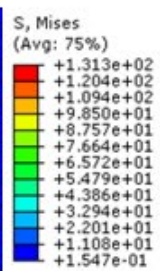

$$
\mathrm{T}=20^{\circ} \mathrm{C}
$$

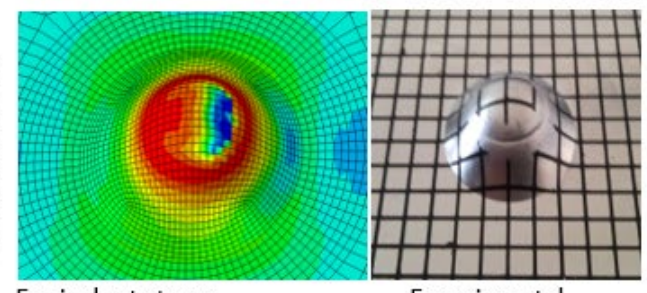

Experimental

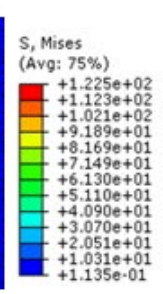

$\mathrm{T}=100^{\circ} \mathrm{C}$

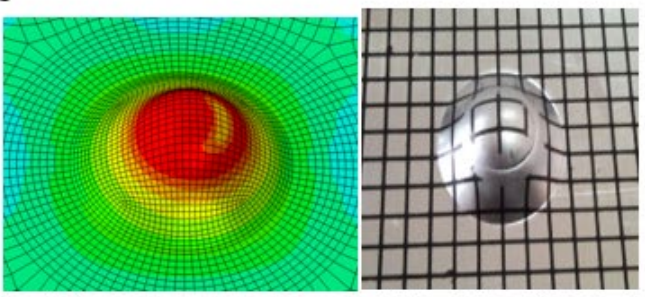

Equivalent stress

Experimental

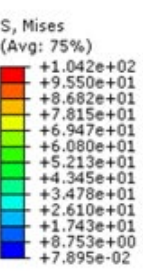

$\mathrm{T}=150^{\circ} \mathrm{C}$

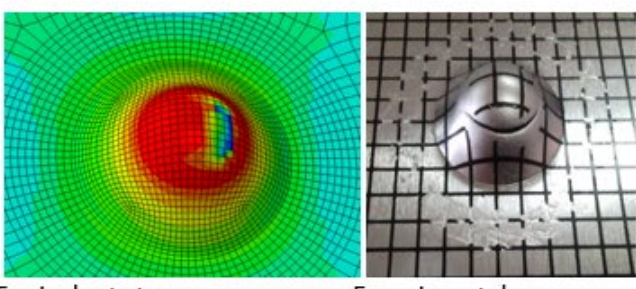

Equivalent stress

Experimental

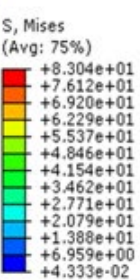

Equivalent stress

$\mathrm{T}=200^{\circ} \mathrm{C}$

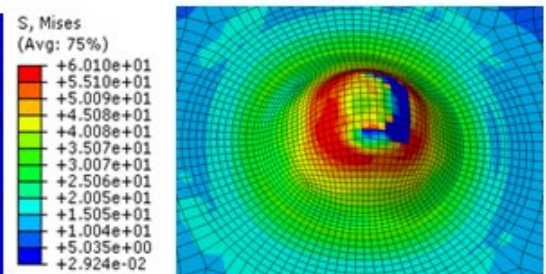

Equivalent stress $\mathbf{T}=\mathbf{2 5 0} 0^{\circ} \mathrm{C}$

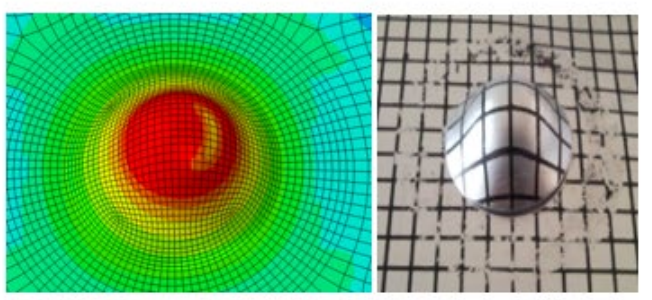

Experimental

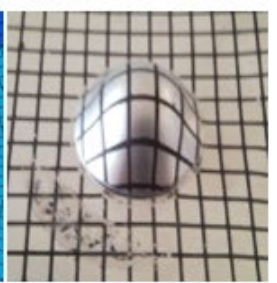

Experimental

Figure 12: Isovalues of equivalent stress and equivalent plastic strain for 1050A Aluminum (under the isothermal condition)

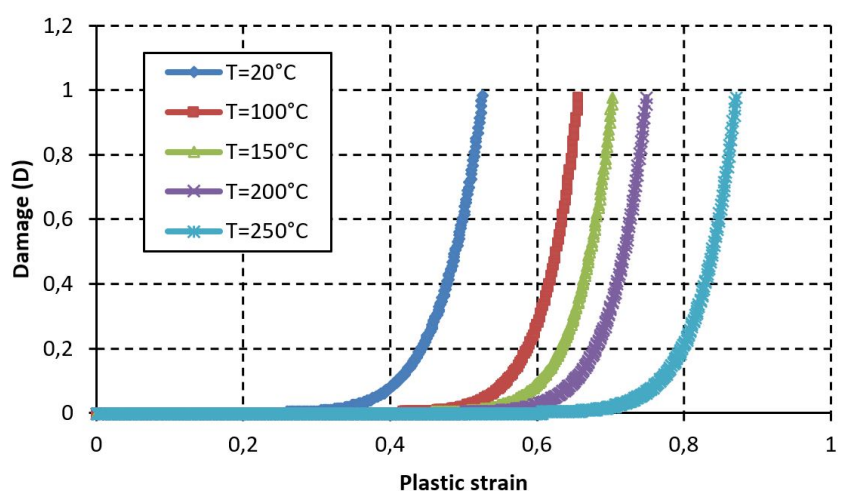

Figure 13: Damage-plastic strain variation of 1050A Aluminum for different isothermal conditions 


\subsubsection{Bulge test}

In the present step, the bulge test will be used to double check the validity of the Swift model coupled to damage which was previously validated by (a part of) Erichsen test results in above section. Hence, the Swift model coupled to the damage is used to numerically predict the formability and damage characteristics of aluminum 1050A at three temperatures $\left(15{ }^{\circ} \mathrm{C}, 50^{\circ} \mathrm{C}\right.$ and $100^{\circ} \mathrm{C}$ ) as done for the bulge test. The correlations (Figure 8 and Figure 9) were used to calculate the Swift model parameters: $\mathrm{K}(\mathrm{T}), \mathrm{n}(\mathrm{T}), \varepsilon \mathrm{u}(\mathrm{T})$ and $\mathrm{\gamma}(\mathrm{T})$ for the temperatures $15^{\circ} \mathrm{C}, 50^{\circ} \mathrm{C}$ and $100^{\circ} \mathrm{C}$.

Table 7 summarizes the values of the hardening and damage parameters calculated according to the models obtained by the method of the linear regressions for the Erichsen test.

Table 7 Parameters of materials at temperatures $15^{\circ} \mathrm{C}, 50^{\circ} \mathrm{C}$ and $100^{\circ} \mathrm{C}$.

\begin{tabular}{|c|c|c|c|c|c|c|}
\hline \multirow{2}{*}{ Temperature $\left({ }^{\circ} \mathrm{C}\right)$} & \multicolumn{3}{|c|}{ Hardening parameters } & \multicolumn{3}{|c|}{ Damage parameters } \\
\hline & $\mathrm{K}(\mathrm{MPa})$ & $\varepsilon_{0}$ & $\mathbf{n}$ & $\varepsilon_{\mathrm{s}}$ & $\varepsilon_{\mathrm{u}}$ & $\gamma$ \\
\hline 15 & 164.687 & 0.01 & 0.306 & 0.01 & 0.543 & 9.933 \\
\hline 50 & 149.42 & 0.01 & 0.292 & 0.01 & 0.585 & 11.295 \\
\hline 100 & 128.301 & 0.009 & 0.252 & 0.004 & 0.662 & 14.409 \\
\hline
\end{tabular}

Figure 14 shows a comparison of the pressure vs height curve between the simulated and experimental results. Before failure occurs, a perfect correlation is observed between the experimental and predicted results. After rupture point, a difference between the two curve is observed. Indeed, post-failure gap between the experimental results and the model results in bulge tests depicted in Figure 14 is increases with the temperature's rise. This may be due to the fluid/sheet interaction not taken into account. Multiphysics model(s) should be built to account for this effect in an independent investigation. Nevertheless, the current investigation provides enough insight into the pre-failure zone. Indeed, there is an agreement between simulated and measured results in a good part of the pre-failure zone.

But, as mentioned above the effect of the fluid-sheet interaction should be taken into account along the effect of the temperature's increase during the bulge test for more predictive accuracy of the failure limit.

\subsection{Thermal gradient and location of the fracture zones}

The assumptions on heat exchange imposed on the sheet specimen are described as follows:

1. radiative and convective mode governing the area undergoing extensional straining.

2. conductive mode controlling the punch/sheet contact

3. conductive mode at the embedded edge subject to temperature regulation

Under above assumptions, a heat flux propagation through the deforming sheet takes place from the clamped edge towards specimen/punch contact area (initially the specimen center). This results in a thermal gradient varying between the maximum heating temperature imposed on the edge and a minimum temperature imposed by contact with the punch, as shown in Table 2.

With the same thermal conditions imposed by the sheet/punch contact, a raise in temperature at the clamped zone produces a pronounced radial thermal gradient (Figure 15). Areas softened by high temperatures become prone to larger plastic deformation and more vulnerable to the development of localized necking and rupture. 

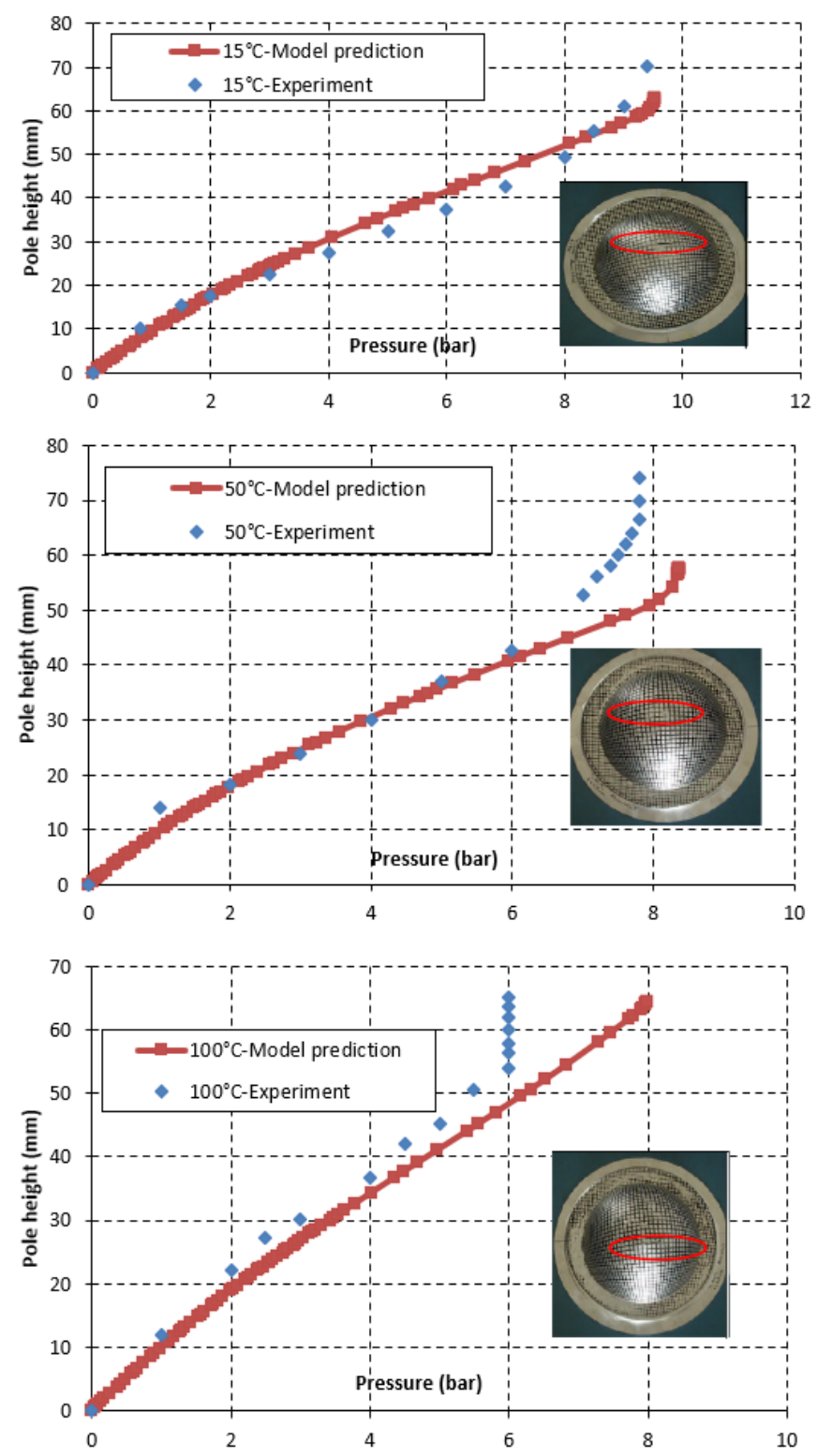

Figure 14: Comparison of the material behavior parameters using modified Swift model predictions and bulge test for three temperatures: $15^{\circ} \mathrm{C}, 50^{\circ} \mathrm{C}$ and $100{ }^{\circ} \mathrm{C}$

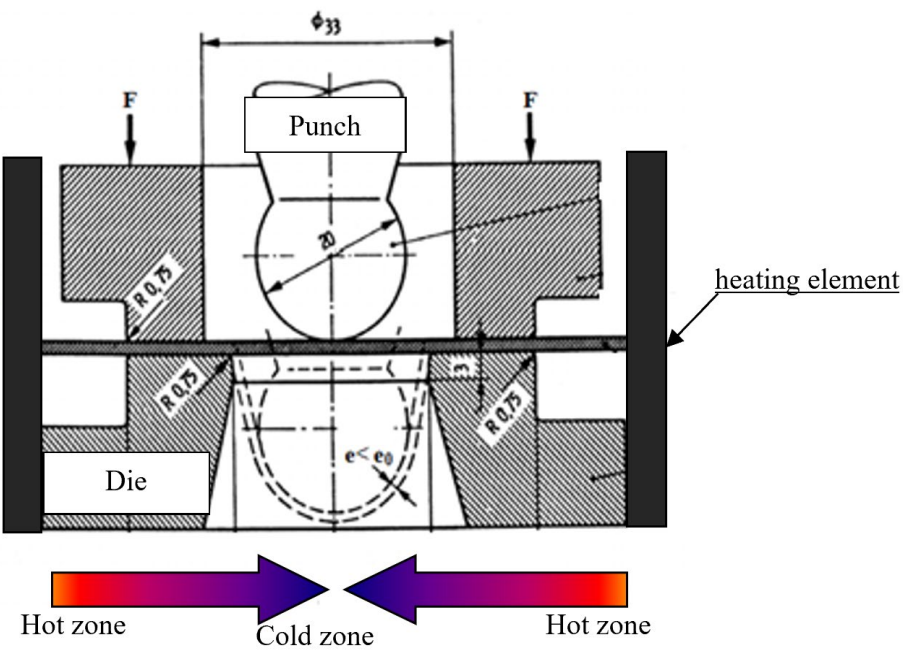

Figure 15: Direction of propagation of the temperature in the blank 
These above assumptions have been proven by numerically simulated tests on sheets subjected to a stationary temperature field with continuous radial variation. Indeed, the assumption of the steady state and the existing symmetries of the test setup (geometry and loading) justify that before the deformation of the sheet, the isotherms are concentric circles representing a radial temperature distribution with a minimum achieved at the limit of the specimen/punch contact. During the test, these isotherms remain concentric, without distortion and centered along the axis of the punch as depicted by the schematic illustration (Figure 16).

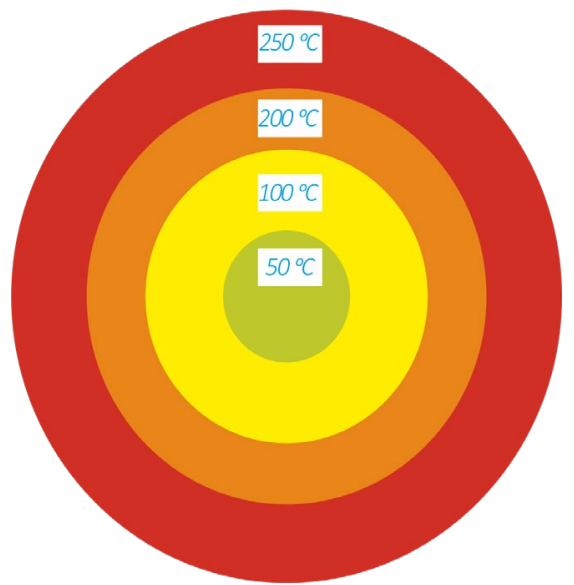

Figure 16: Schematic representation of the thermal loading acting on the sheet specimen (concentric zones with temperatures decreasing from clamped area to central contact zone under isothermal condition)

Figure 17 shows the numerical results of the equivalent strain over the sheet. Two rupture zones are observed. For temperatures below $150{ }^{\circ} \mathrm{C}$, the rupture occurs at the sheet/punch contact zone. Above this temperature, rupture happens in the sheet/blank-holder contact zone. The failure zone's location is obtained based on the analysis of equivalent plastic strain distribution corresponding to the punch displacement closer to the experimental Erichsen Index. The failure zones are the regions of largest plastic strain as revealed in Figure 17 and Figure 18.
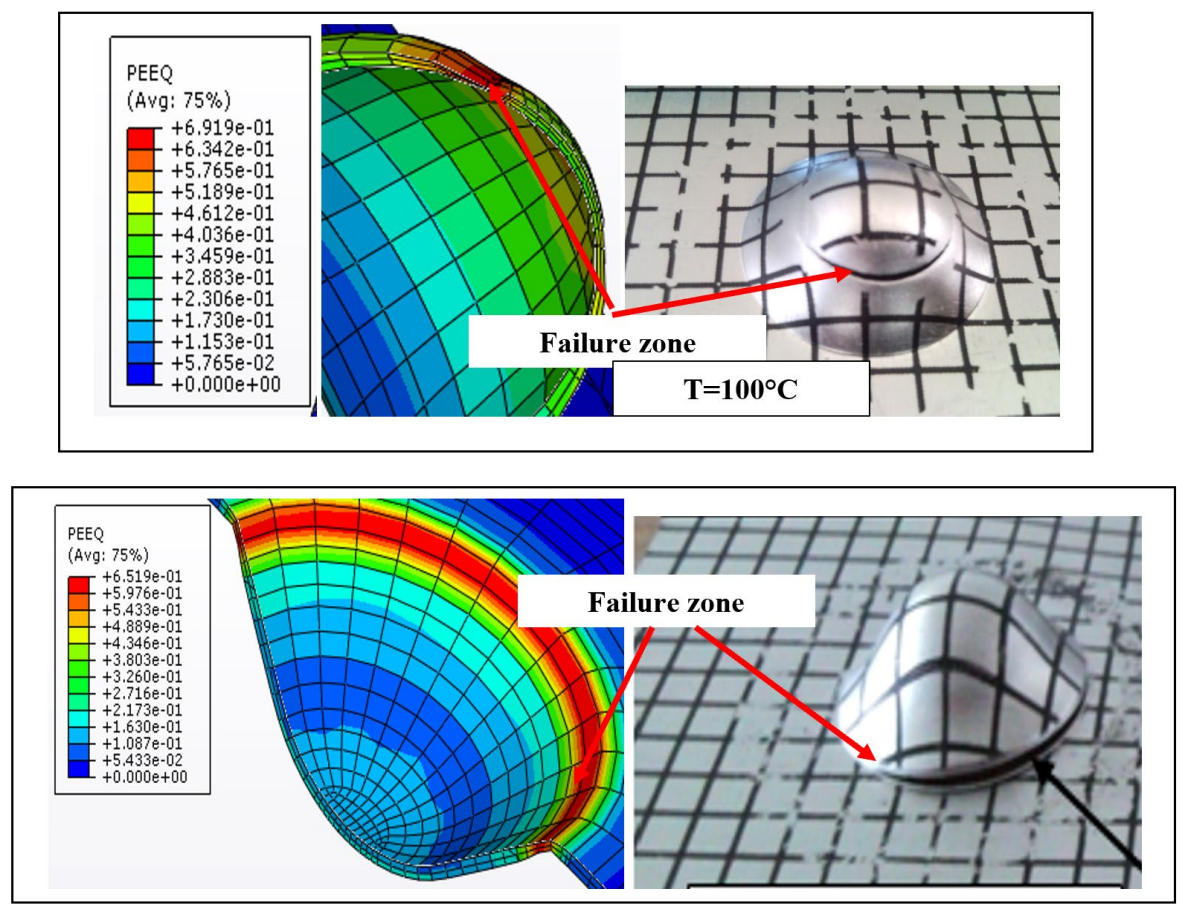

Figure 17: Location of failure zones for different temperatures determined by numerical simulation and compared with the test observations 

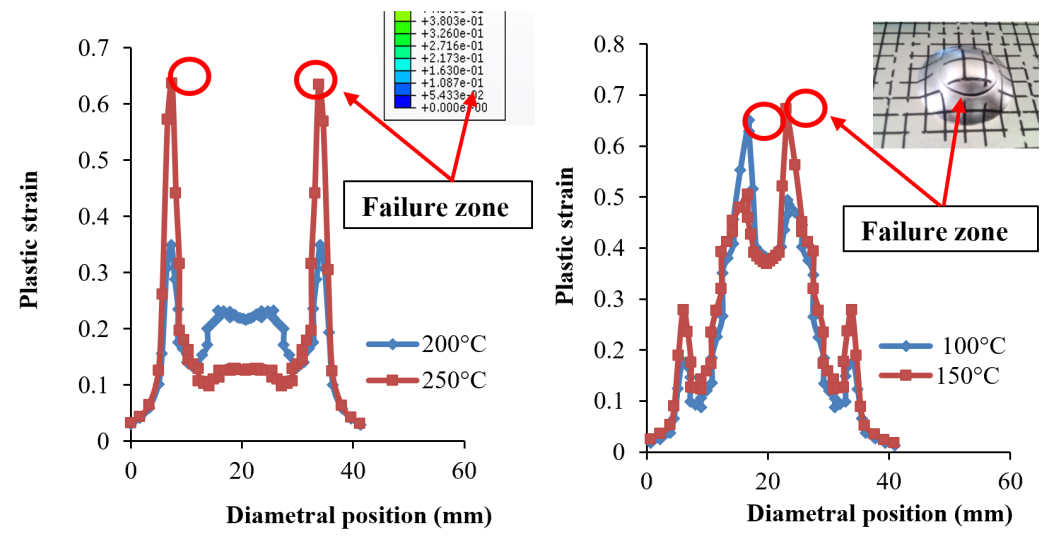

Figure 18: Location of maximum strain on the edge of the punch/die contact area obtained by numerical simulations

\subsection{Correlation between Erichsen index and critical plastic strain}

Considering the coupled modified Swift model, a variation $\Delta \varepsilon_{s}$ of the coefficient $\varepsilon_{s}$ generates a relative variation of the stress as follows:

$$
\frac{\Delta \sigma}{\sigma}=-\gamma \frac{D}{1-D} \frac{\varepsilon_{u}}{\varepsilon_{s}+\varepsilon_{p}} \Delta \varepsilon_{s}
$$

For a cumulated plastic strain equal to $50 \%$ (closer the critical value as shown in Figure 16), an absolute variation of $0.5 \%$ of $\varepsilon_{s}$ generates a relative stress variation of 3.3\% (Eq. 6). The results of the identification show that the largest difference calculated between $\varepsilon_{0}$ and $\varepsilon_{s}$ is about 0.005 (Table 2), which allows to assume the equality of the two coefficients. A reduction in the model parameters' number simplifies the calculation of the critical strain which is a solution of the equation:

$\frac{d \sigma}{d \varepsilon_{p}}=0$

This is expressed by the relation:

$\varepsilon_{P c}=\varepsilon_{u}\left(\frac{n}{n+\gamma \varepsilon_{u}}\right)^{1 / \gamma}-\varepsilon_{o}$

Figure 19 illustrates that this critical strain, which depends only on the coefficients of the model, makes it possible to measure the influence of temperature on the formability of 1050A aluminum in the same way as the Erichsen Index. Indeed, the two characteristics expressing the formability of the material as a function of the temperature can be correlated through the exponential law:

$\operatorname{IE}(T)=7.09 \exp \left(0.632 \varepsilon_{p c}(T)\right)$

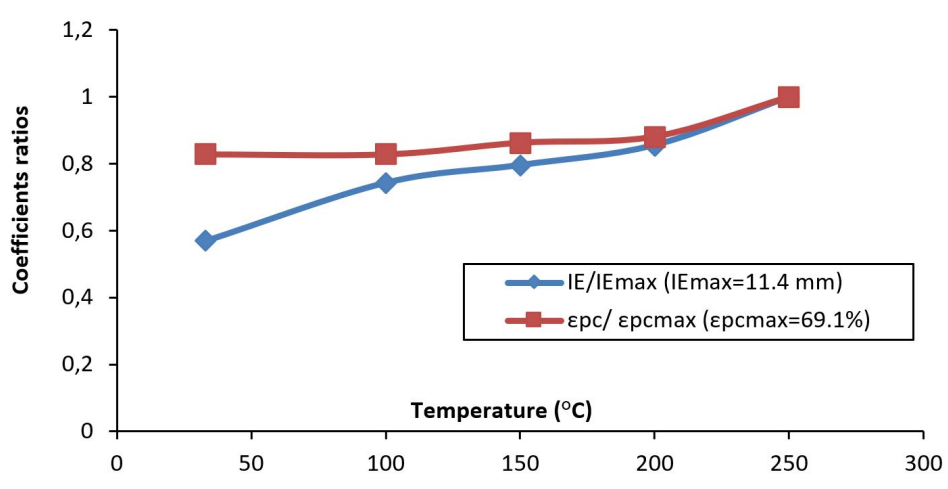

Figure 19: Influence of temperature on the formability of 1050A Aluminum 
It is worthy noting that unlike the Erichsen index which is an aggregate measure of the formability of sheet metal, the critical strain is similar to a local forming limit indicator. This is of practical interest to evaluate the impact of temperature on the forming process. Taking the critical strain given by equation (22) as a local forming limit, the results of the identification can be extrapolated to control the problems relating to the prediction of failure zones, the minimization of the spring-back and the creation of new developed surface during a sheet forming process.

\section{CONCLUSION}

The study has highlighted the beneficial effects of sheet metals' heating during forming process on the elastoplastic behavior of 1050A aluminum sheets. Furthermore, it is noteworthy to recall other relevant results of the present experimental/numerical investigation:

- A mathematical correlation between the Erichsen index and the plastic strain flow which allows a global measure of formability using a local measure.

- Adopting equation (4) as forming limit criterion, the correlation between Erichsen Index and critical strain can contribute to a rapid estimate of forming limit curves taking into account the temperature by a simple measurement of Erichsen Index and sheet anisotropy coefficients.

- The identification methods/results are successfully validated by the bulge test.

- The results of the identification may be utilized to numerically conduct/control simulations of forming operations (such as stamping, drawing, forming, and incremental forming) for sheet metals with thermal elastoplastic behavior coupled to damage.

- As future extension to this work, a comparative study is needed to compare experimental results with those using hot incremental forming tests.

\section{Acknowledgement}

The authors would acknowledge the financial support from the Deanship of Scientific Research at the Northern Border University to accomplish the present research project under the grant number ENG-2019-3-9-F-7984.

Author's Contributions: Conceptualization, N Ghazouani, MT Nasri; Methodology, MA Tashkandi, MT Nasri; Investigation, A Eladeb, MT Nasri; Writing - original draft, A Eladeb, MT Nasri ; Writing - review \& editing, N Ghazouani, M A Tashkandi; Funding acquisition, N Ghazouani; Resources, A Eladeb; Supervision, N Ghazouani.

Editor: Marcílio Alves.

\section{References}

Abbassi, F., Belhadj, T., Mistou, S., \& Zghal, A. (2013). Parameter identification of a mechanical ductile damage using Artificial Neural Networks in sheet metal forming. Materials \& Design 45: 605-615. Elsevier.

Ablat, M. A., \& Qattawi, A. (2017). Numerical simulation of sheet metal forming: A review. The International Journal of Advanced Manufacturing Technology 89(1-4): 1235-1250.

Achouri, M., Germain, G., Dal Santo, P., \& Saidane, D. (2014). Experimental and numerical analysis of micromechanical damage in the punching process for High-Strength Low-Alloy steels. Materials \& Design (1980-2015) 56: 657-670. Elsevier.

Aguir, H., Chamekh, A., BelHadjSalah, H., Dogui, A., \& Hambli, R. (2009). Parameter identification of a non-associative elastoplastic constitutive model using ANN and multi-objective optimization. International Journal of Material Forming 2(2): 75-82.

Aguir, Hamdi, BelHadjSalah, H., \& Hambli, R. (2011). Parameter identification of an elasto-plastic behaviour using artificial neural networks-genetic algorithm method. Materials \& Design 32(1): 48-53. Elsevier.

Ahmad, M., Curiel-Sosa, J., Arun, S., \& Rongong, J. (2019). An enhanced void-crack-based Rousselier damage model for ductile fracture with the XFEM. International Journal of Damage Mechanics 28(6): 943-969.

Atkinson, M. (1997). Accurate determination of biaxial stress-Strain relationships from hydraulic bulging tests of sheet metals. International Journal of Mechanical Sciences 39(7): 761-769. 
Ayadi, M., Rezgui, M. A., Cherouat, A., Slimani, F., \& Nasri, M. T. (2009). Contribution à la modélisation expérimentale et numérique des instabilités plastiques en hydroformage des tôles minces. Mécanique \& Industries 10(6): 503-518.

Badreddine, H., Saanouni, K., \& Dogui, A. (2010). On non-associative anisotropic finite plasticity fully coupled with isotropic ductile damage for metal forming. International Journal of Plasticity 26(11): 1541-1575.

Banabic, D. (2016). Advances in Plastic Anisotropy and Forming Limits in Sheet Metal Forming. Journal of Manufacturing Science and Engineering 138(9): 090801.

Banabic, D., Barlat, F., Cazacu, O., \& Kuwabara, T. (2010). Advances in anisotropy and formability. International Journal of Material Forming 3(3): 165-189.

Banabic, D., Barlat, F., Cazacu, O., \& Kuwabara, T. (2020). Advances in anisotropy of plastic behaviour and formability of sheet metals. International Journal of Material Forming 13(5): 749-787.

Banabic, D., Bunge, H.-J., Pöhlandt, K., \& Tekkaya, A. E. (2000). Formability of Metallic Materials. (D. Banabic, Ed.)Engineering Materials. Berlin, Heidelberg: Springer Berlin Heidelberg. Retrieved October 3, 2020, from http://link.springer.com/10.1007/978-3-662-04013-3

Barlat, F. (1987). Crystallographic texture, anisotropic yield surfaces and forming limits of sheet metals. Materials Science and Engineering 91: 55-72.

Barlat, F., Aretz, H., Yoon, J. W., Karabin, M. E., Brem, J. C., \& Dick, R. E. (2005). Linear transfomation-based anisotropic yield functions. International Journal of Plasticity 21(5): 1009-1039.

Barlat, F., Brem, J. C., Yoon, J. W., Chung, K., Dick, R. E., Lege, D. J., Pourboghrat, F., et al. (2003). Plane stress yield function for aluminum alloy sheets-part 1: Theory. International Journal of Plasticity 19(9): 1297-1319.

Barlat, F., \& Lian, K. (1989). Plastic behavior and stretchability of sheet metals. Part I: A yield function for orthotropic sheets under plane stress conditions. International Journal of Plasticity 5(1): 51-66.

Barlat, Frédéric, Jeong, Y., Ha, J. J., Tomé, C., Lee, M. G., \& Wen, W. (2016). Advances in Constitutive Modeling of Plasticity for Forming Applications. Key Engineering Materials 725: 3-14.

Barlat, Frédéric, Lege, D. J., \& Brem, J. C. (1991). A six-component yield function for anisotropic materials. International Journal of Plasticity 7(7): 693-712.

Ben Othmen, K., Haddar, N., Jegat, A., Manach, P.-Y., \& Elleuch, K. (2020). Ductile fracture of AISI 304L stainless steel sheet in stretching. International Journal of Mechanical Sciences 172: 105404.

Bong, H. J., \& Lee, J. (2020). Crystal Plasticity Finite Element-Marciniak-Kuczynski Approach with Surface Roughening Effect in Predicting Formability of Ultra-Thin Ferritic Stainless Steel Sheets. International Journal of Mechanical Sciences 106066.

van den Boogaard, A. H. (2004). Thermally enhanced forming of aluminium sheet: Modelling and experiments.

Chaboche, J. L. (1986). Time-independent constitutive theories for cyclic plasticity. International Journal of Plasticity 2(2): 149-188.

Chaboche, J. L. (1988). Continuum Damage Mechanics: Part I-General Concepts. Journal of Applied Mechanics 55(1): 59-64. American Society of Mechanical Engineers Digital Collection.

Chakraborti, N. (2004). Genetic algorithms in materials design and processing. International Materials Reviews 49(3-4): 246260. Taylor \& Francis.

Cherouat, A., Borouchaki, H., \& Jie, Z. (2018). Simulation of Sheet Metal Forming Processes Using a Fully Rheological-Damage Constitutive Model Coupling and a Specific 3D Remeshing Method. Metals 8(12): 991.

Cooper, D. R., Rossie, K. E., \& Gutowski, T. G. (2017). The energy requirements and environmental impacts of sheet metal forming: An analysis of five forming processes. Journal of Materials Processing Technology 244: 116-135.

Gao, T., Ying, L., Hu, P., Han, X., Rong, H., Wu, Y., \& Sun, J. (2020). Investigation on mechanical behavior and plastic damage of AA7075 aluminum alloy by thermal small punch test: Experimental trials, numerical analysis. Journal of Manufacturing Processes 50: 1-16.

Gassara, F., Hambli, R., Bouraoui, T., Halouani, F. E., \& Soulat, D. (2009). Optimization of springback in L-bending process using a coupled Abaqus/Python algorithm. The International Journal of Advanced Manufacturing Technology 44(1-2): 61-67.

Gatea, S., Ou, H., Lu, B., \& McCartney, G. (2017). Modelling of ductile fracture in single point incremental forming using a modified GTN model. Engineering Fracture Mechanics 186: 59-79. 
Ghorbel, O., Mars, J., Koubaa, S., Wali, M., \& Dammak, F. (2019). Coupled anisotropic plasticity-ductile damage: Modeling, experimental verification, and application to sheet metal forming simulation. International Journal of Mechanical Sciences 150: 548-560.

Gorji, M. B., Mozaffar, M., Heidenreich, J. N., Cao, J., \& Mohr, D. (2020). On the potential of recurrent neural networks for modeling path dependent plasticity. Journal of the Mechanics and Physics of Solids 143: 103972.

Hill, R. (1948). A theory of the yielding and plastic flow of anisotropic metals. (1948). Proceedings of the Royal Society of London. Series A. Mathematical and Physical Sciences 193(1033): 281-297.

Hu, Q., Li, X., \& Chen, J. (2018). New robust algorithms for Marciniak-Kuczynski model to calculate the forming limit diagrams. International Journal of Mechanical Sciences 148: 293-306.

Hussain, G., \& Gao, L. (2007). A novel method to test the thinning limits of sheet metals in negative incremental forming. International Journal of Machine Tools and Manufacture 47(3-4): 419-435.

Keum, Y. T., \& Lee, K. B. (2000). Sectional finite element analysis of forming processes for aluminum-alloy sheet metals. International Journal of Mechanical Sciences 42(10): 1911-1933.

Koç, M., \& Altan, T. (2001). An overall review of the tube hydroforming (THF) technology. Journal of Materials Processing Technology 108(3): 384-393. Elsevier.

Lee, E.-H., Choi, H., Stoughton, T. B., \& Yoon, J. W. (2019). Combined anisotropic and distortion hardening to describe directional response with Bauschinger effect. International Journal of Plasticity 122: 73-88.

Lee, E.-H., Stoughton, T. B., \& Yoon, J. W. (2017). A yield criterion through coupling of quadratic and non-quadratic functions for anisotropic hardening with non-associated flow rule. International Journal of Plasticity 99: 120-143.

Lee, S. Y., Keum, Y. T., Chung, K., Park, J. M., \& Barlat, F. (1997). Three-dimensional finite-element method simulations of stamping processes for planar anisotropic sheet metals. International Journal of Mechanical Sciences 39(10): 1181-1198.

Lemaitre, J. (1985). A Continuous Damage Mechanics Model for Ductile Fracture. Journal of Engineering Materials and Technology 107(1): 83-89. American Society of Mechanical Engineers Digital Collection.

Lemaitre, J., \& Chaboche, J.-L. (1994). Mechanics of Solid Materials. Cambridge University Press.

Lestriez, P., Saanouni, K., Mariage, J. F., \& Cherouat, A. (2004). Numerical Prediction of Ductile Damage in Metal Forming Processes Including Thermal Effects. International Journal of Damage Mechanics 13(1): 59-80.

$\mathrm{Li}, \mathrm{X} .$, \& He, D. (2013). Identification of material parameters from punch stretch test. Transactions of Nonferrous Metals Society of China 23(5): 1435-1441. Elsevier.

Lu, H., Liu, H., \& Wang, C. (2019). Review on strategies for geometric accuracy improvement in incremental sheet forming. The International Journal of Advanced Manufacturing Technology 102(9-12): 3381-3417.

Mahabunphachai, S., \& Koç, M. (2008). Investigation of size effects on material behavior of thin sheet metals using hydraulic bulge testing at micro/meso-scales. International Journal of Machine Tools and Manufacture 48(9): 1014-1029.

Manesh, H. D., \& Taheri, A. K. (2003). Bond strength and formability of an aluminum-clad steel sheet. Journal of Alloys and Compounds 361(1-2): 138-143.

Mohamed, M., Elatriby, S., Shi, Z., \& Lin, J. G. (2016). Prediction of Forming Limit Diagram for AA5754 Using Artificial Neural Network Modelling. Key Engineering Materials 716: 770-778.

Msolli, S., Badreddine, H., Labergere, C., Martiny, M., Robin, G., Jrad, M., Saanouni, K., et al. (2015). Experimental characterization and numerical prediction of ductile damage in forming of AA1050-O sheets. International Journal of Mechanical Sciences 99: 262-273.

Naceur, H., Guo, Y. Q., \& Ben-Elechi, S. (2006). Response surface methodology for design of sheet forming parameters to control springback effects. Computers \& structures 84(26-27): 1651-1663. Elsevier.

Nakagawa, T. (2000). Advances in prototype and low volume sheet forming and tooling. Journal of Materials Processing Technology 98(2): 244-250.

Park, N., Stoughton, T. B., \& Yoon, J. W. (2019). A criterion for general description of anisotropic hardening considering strength differential effect with non-associated flow rule. International Journal of Plasticity 121: 76-100.

Pradeau, A. (2018). Anisotropic behaviour and fracture for sheet metals under associated and non-associated flow plasticity 144 
Rajhi, W., Saanouni, K., \& Sidhom, H. (2014). Anisotropic ductile damage fully coupled with anisotropic plastic flow: Modeling, experimental validation, and application to metal forming simulation. International Journal of Damage Mechanics 23(8): 1211-1256.

Robert, L., Velay, V., Decultot, N., \& Ramde, S. (2012). Identification of hardening parameters using finite element models and full-field measurements: Some case studies. The Journal of Strain Analysis for Engineering Design 47(1): 3-17.

Saanouni, K., Belamri, N., \& Autesserre, P. (2010). Finite element simulation of 3D sheet metal guillotining using advanced fully coupled elastoplastic-damage constitutive equations. Finite Elements in Analysis and Design 46(7): 535-550.

Saanouni, K., \& Hamed, M. (2013). Micromorphic approach for finite gradient-elastoplasticity fully coupled with ductile damage: Formulation and computational aspects. International Journal of Solids and Structures 50(14-15): 2289-2309.

Saanouni, K. (2012). Damage mechanics in metal forming: Advanced modeling and numerical simulation. London : Hoboken, NJ: ISTE Ltd; John Wiley \& Sons.

Saanouni, K., Cherouat, A., \& Hammi, Y. (2001). Numerical aspects of finite elastoplasticity with isotropic ductile damage for metal forming. Revue Européenne des Éléments Finis 10(2-4): 327-351.

Stoughton, T. B. (2002). A non-associated flow rule for sheet metal forming. International Journal of Plasticity 18(5-6): 687-714.

Stoughton, T. B., \& Yoon, J. W. (2009). Anisotropic hardening and non-associated flow in proportional loading of sheet metals. International Journal of Plasticity 25(9): 1777-1817.

Stoughton, T. B., \& Yoon, J.-W. (2004). A pressure-sensitive yield criterion under a non-associated flow rule for sheet metal forming. International Journal of Plasticity 20(4-5): 705-731.

Takuda, H., Mori, K., Takakura, N., \& Yamaguchi, K. (2000). Finite element analysis of limit strains in biaxial stretching of sheet metals allowing for ductile fracture. International Journal of Mechanical Sciences 42(4): 785-798.

Teaca, M., Charpentier, I., Martiny, M., \& Ferron, G. (2010). Identification of sheet metal plastic anisotropy using heterogeneous biaxial tensile tests. International Journal of Mechanical Sciences 52(4): 572-580.

Tisza, M., \& Czinege, I. (2018). Comparative study of the application of steels and aluminium in lightweight production of automotive parts. International Journal of Lightweight Materials and Manufacture 1(4): 229-238.

US EPA, O. (2016, May 4). Highlights of the Automotive Trends Report. US EPA. Data and Tools, . Retrieved October 3, 2020, from https://www.epa.gov/automotive-trends/highlights-automotive-trends-report

Varma, N. S. P., Narasimhan, R., Luo, A. A., \& Sachdev, A. K. (2007). An analysis of localized necking in aluminium alloy tubes during hydroforming using a continuum damage model. International journal of mechanical sciences 49(2): 200-209. Elsevier.

Xiao, R. (2019). A Review of Cruciform Biaxial Tensile Testing of Sheet Metals. Experimental Techniques 43(5): 501-520.

N'jock, MY., Badreddine, H., Labergere, C., Yue, Z., Saanouni, K., \& Dang, V.-T. (2020). An application of fully coupled ductile damage model considering induced anisotropies on springback prediction of advanced high strength steel materials. International Journal of Material Forming. Retrieved October 6, 2020, from http://link.springer.com/10.1007/s12289-020-01582-9

Yoon, J. (1999). A general elasto-plastic finite element formulation based on incremental deformation theory for planar anisotropy and its application to sheet metal forming. International Journal of Plasticity 15(1): 35-67.

Yoon, J. W., Song, I. S., Yang, D. Y., Chung, K., \& Barlat, F. (1995). Finite element method for sheet forming based on an anisotropic strain-rate potential and the convected coordinate system. International Journal of Mechanical Sciences 37(7): 733-752.

Yoon, J.-W., Pourboghrat, F., Chung, K., \& Yang, D.-Y. (2002). Springback prediction for sheet metal forming process using a 3D hybrid membrane/shell method. International Journal of Mechanical Sciences 44(10): 2133-2153.

Yoshida, F., Urabe, M., \& Toropov, V. V. (1998). Identification of material parameters in constitutive model for sheet metals from cyclic bending tests. International Journal of Mechanical Sciences 40(2-3): 237-249.

Yue, Z., Cao, K., Badreddine, H., Saanouni, K., \& Gao, J. (2019). Failure prediction on steel sheet under different loading paths based on fully coupled ductile damage model. International Journal of Mechanical Sciences 153-154: 1-9.

Zhang, K., Badreddine, H., \& Saanouni, K. (2018). Thermomechanical modeling of distortional hardening fully coupled with ductile damage under non-proportional loading paths. International Journal of Solids and Structures 144-145: 123-136.

Zhang, K., Badreddine, H., \& Saanouni, K. (2019). Thermodynamically-consistent constitutive modeling of hardening asymmetry including isotropic ductile damage for Mg alloys. European Journal of Mechanics-A/Solids 73: 169-180. 
Zhang, R., Shao, Z., \& Lin, J. (2018). A review on modelling techniques for formability prediction of sheet metal forming. International Journal of Lightweight Materials and Manufacture 1(3): 115-125.

Zheng, K., Lee, J., Lin, J., \& Dean, T. A. (2017). A buckling model for flange wrinkling in hot deep drawing aluminium alloys with macro-textured tool surfaces. International Journal of Machine Tools and Manufacture 114: 21-34.

Zhuang, X., Wang, T., Zhu, X., \& Zhao, Z. (2016). Calibration and application of ductile fracture criterion under nonproportional loading condition. Engineering Fracture Mechanics 165: 39-56.

Zribi, T., Khalfallah, A., \& BelHadjSalah, H. (2013). Experimental characterization and inverse constitutive parameters identification of tubular materials for tube hydroforming process. Materials \& Design 49: 866-877. Elsevier. 